\title{
Mortality in miners and millers of crocidolite in Western Australia
}

\author{
B K ARMSTRONG, ' N H DE KLERK, ' A W MUSK, ${ }^{2}$ M S T HOBBS ${ }^{3}$ \\ From the National Health and Medical Research Council Research Unit in Epidemiology and Preventive \\ Medicine, 'Department of Medicine, University of Western Australia, Perth, the Department of Respiratory \\ Medicine, ${ }^{2}$ Sir Charles Gairdner Hospital, Nedlands, and Unit of Clinical Epidemiology, ${ }^{3}$ Department of \\ Medicine, University of Western Australia, Perth, Western Australia
}

ABSTRACT It is known that 6505 men and 411 women were employed in the mining and milling of crocidolite at Wittenoom in the Pilbara region of Western Australia between 1943 and 1966. Employment was usually brief (median duration four months) and exposure intense (median estimated cumulative exposure 6 fibres/cc years). The vital status of $73 \%$ of the men and $58 \%$ of the women employed in the industry was known at 31 December 1980, providing 95264 person-years of follow up with 820 deaths in men and 4914 person-years with 23 deaths in women. The standardised mortality ratio (SMR) for all causes in men was 1.53 (95\% confidence interval 1.43 to 1.64$)$. Statistically significant excess death rates were observed in men for neoplasms, particularly malignant mesothelioma (32 deaths), neoplasms of the trachea, bronchus, and lung (SMR 2.64), and neoplasms of the stomach (SMR 1.90); respiratory diseases, particularly pneumoconiosis (SMR 25.5); infections, particularly tuberculosis (SMR 4.09); mental disorders particularly alcoholism (SMR 4.87); digestive diseases, particularly peptic ulceration (SMR 2.46) and cirrhosis of the liver (SMR 3.94); and injuries and poisonings, particularly non-transport accidents (SMR 2.36). The excess mortality from pneumoconiosis, malignant mesothelioma, and respiratory cancers, but not stomach neoplasms, was dependent on time since first exposure and cumulative exposure. There was no increase in mortality from laryngeal cancer (SMR 1.09) or neoplasms other than those listed. The SMR for all causes in women was 1.47 (95\% confidence interval 0.98-2.21) and for neoplasms 1.99; there was one death from malignant pleural mesothelioma.

Numerous epidemiological studies have examined the effects of exposure to asbestos of different types.'. Few, however, have dealt with exposure to crocidolite alone. They have included follow up studies of wartime gas mask workers in Nottingham ${ }^{23}$ and Leyland $^{4}$ in England, where West Australian crocidolite was used, and Ottawa, ${ }^{5}$ Canada, where the source of the crocidolite was not stated. The proportion of female workers in these studies ranged from $45 \%{ }^{5}$ to $100 \% .^{3}$ All studies showed high mortality from mesothelioma and some showed increased mortality from ovarian cancer ${ }^{34}$ The effects of exposure to South African crocidolite have been examined through a case series ${ }^{6}$ and a cross sectional survey, ${ }^{7}$ both studies indicating probably high mesothelioma mortality rates. A recent study comparing mortality

Accepted 4 December 1986 rates in crocidolite mining districts with other districts in South Africa also showed high death rates from "asbestosis and/or mesothelioma" as well as excesses of deaths from lung cancer, stomach cancer, and tuberculosis. $^{8}$

Crocidolite was mined at Wittenoom Gorge in Western Australia from 1937 until 1966. From 1943 until 1966 the principal leases were mined by a single company, Australian Blue Asbestos (ABA), which employed over 6000 people, mostly for short periods. This population provides an opportunity to study the effects of a short period of intense exposure to crocidolite alone as few employees had other asbestos exposure in mining or manufacturing industries and most stayed in Western Australia so that it has been possible to determine their present vital status. Measurements of dust concentrations in the industry in a survey conducted in 1966 permit examination of 
the relation between fibre concentration and mortality in this population.

Previous follow up of this cohort to the end of 1977 showed increased mortality from pneumoconiosis, malignant pleural mesothelioma, and bronchogenic carcinoma. ${ }^{9}$ The increases were related to duration and intensity of exposure to crocidolite and time since exposure began. At that time there had been no deaths from malignant peritoneal mesothelioma recorded in this population and there was no excess of deaths from gastrointestinal cancer. In the current study we have extended follow up to the end of 1980 and undertaken searches of death registries in all states of Australia to provide more accurate data on mortality.

\section{Subjects}

Data on employees of ABA were obtained from employment records of the company and supplemented by records of subscribers to a mineworkers benevolent fund (The Western Australian Mineworkers Relief Fund). Name, date of birth, age at first employment, nationality, dates of employment, and occupations at Wittenoom were recorded whenever possible. Additional data were obtained from records of subjects presenting themselves for compulsory chest radiographs taken by the Perth Chest Clinic. A cohort of 6506 male and 411 female employees was assembled.

\section{Methods}

DETERMINATION OF VITAL STATUS

The names of all workers in the cohort were searched for in death registries in all states of Australia from 1 January 1943 to 31 December 1980 , all state and Commonwealth electoral rolls current in 1981 or later, all Australian telephone directories current in 1982 or later, and records of permanent departure overseas in the period 1972-8 held by the Australian Department of Immigration. The names were also searched for in records of the pneumoconiosis boards and cancer registries of Western Australia, New South Wales, Victoria, and South Australia, the principal public hospitals in Western Australia, and the motor vehicle drivers licensing authorities in Western Australia, South Australia, and New South Wales. Matches between names of people in the cohort and names in these records were accepted only after clerical inspection of all identifying data in potentially matched records. Use of records of hospital and cancer registries for the determination of vital status meant that subjects who had been ill were more likely to be traced than those who had not.
ESTIMATION OF CUMULATIVE EXPOSURE TO CROCIDOLITE FIBRES

Measurements of dust concentrations in the air of the mine and mill at Wittenoom were made periodically between 1948 and 1958 by the Mines Department of Western Australia usìng a koniometer. Only total dust particles per cubic centimetre (ppcc) were counted and the upper measurement limit of 1000 ppcc was often exceeded. These measurements suggest that there was little change in total dust concentration in this period, at least until a new mill was commissioned in September 1957. Anecdotal information indicates that the Mines Department inspections were often preceded by a shut down of operations.

The concentrations of airborne respirable fibres of crocidolite greater than 5 microns in length were measured in various workplaces in a survey undertaken for the Mines Department in $1966 .{ }^{10}$ Samples for counting the number of fibres were taken with a Casella long running thermal precipitator. The duration of most samples was between four and five hours. A Casella gravimetric dust sampler and a Hexhlet were used to collect dust to estimate mass. Fibre concentrations varied from 20 fibres per cubic centimeter (f/cc) in certain parts of the mine to $100 \mathrm{f} / \mathrm{cc}$ in the bagging area of the mill. The ratio of fibres greater than 5 microns in length to total particles varied from $1.3 \%$ to $4.0 \%$ in the same areas.

Using the judgement of an ex-superintendent of operations at Wittenoom (who had a detailed knowledge of all jobs on the site throughout the production period) all 87 job categories in the various workplaces were graded on a 0 to 10 scale of estimated fibre levels for both before and after September 1957 when a less dusty mill started operating. This grading was verified by the industrial hygienist who was responsible for the 1966 survey and again by the exsuperintendent. By equating the grades of the workplaces with fibre levels known from the 1966 survey it was possible to estimate, by linear interpolation, the likely fibre concentrations applying to other job/workplace combinations. Each subject's cumulative exposure was then calculated in fibre years per cubic centimetre (f/ccy) by adding over all their different jobs the product of fibre concentration for that job and the length of time in the job.

\section{MORTALITY}

Expected numbers of deaths in the cohort were calculated by the man-years method" by use of age, period, cause, and sex specific death rates for Western Australia. These rates were prepared for this study from annual tabulations of deaths prepared by the Australian Bureau of Statistics. The calendar periods adopted were designed to begin or end with years of change from one revision of the International Clas- 
sification of Disease (ICD) to the next. The first period was 1950-3 and death rates for this period were used to calculate expected numbers of deaths in all personyears accumulated from 1943 to 1953 . SMRs were then calculated as the ratio of observed to expected deaths. Because of the high proportion of subjects who were not traced to the end of 1980 , most of whom were not traced beyond the end of employment at Wittenoom (see below), and the substantially complete ascertainment of deaths (at least in Australia), conventional methods of calculation will probably give rise to an overestimate of mortality. To demonstrate this likely bias and to provide maximum and minimum estimates of the effects of crocidolite exposure, expected numbers of deaths were calculated with two different censoring dates: 31 December 1980 for SMR1 and the date last known to be alive for SMR2. The former assumes that all subjects who were lost to follow up were alive at this date. All subjects were censored at age 85 if they were not known to have died before that age.

To illustrate possible effects of cumulative exposure to crocidolite on mortality, death rates for different causes, directly standardised to the world population of Doll, ${ }^{12}$ were calculated within groupings of time since first exposure and total cumulative exposure.

\section{Results}

CHARACTERISTICS OF THE WORKFORCE

Staff were first employed by ABA at Wittenoom in 1943 and the last terminated employment there in 1967 (table 1). Most were employed after the new mill was started in 1957; the median year of first employment was 1959. Most subjects began work at Wittenoom before age 30 and worked there for less than one year. Indeed 19\% worked there for less than a month, a reflection, perhaps, of the poor working and living conditions ${ }^{13}$ The median duration of employment was four months. Most of the workforce was of Australian or British origin. The category "Australian or British" (table 1) refers to people who gave their nationality as "British." It was common at the time for those born in Australia of British origin to consider themselves British and death certificates indicate that some $39 \%$ of those so classified on work history sheets were born in Australia.

Most men worked in the mine or mill and sometimes both (table 1). In total, $31 \%$ of those with a known worksite worked in the mill, the site of heaviest crocidolite exposure, at some time. Most women, although employed by ABA, did not work in the mine or the mill, or even elsewhere on the site of operations, but in the town $(80 \%$ of those with known worksite). Two women had worked in the mine as surveying assistants and two in the mill, one as a millhand and
Table 1 Percentage distributions of subjects by demographic and work related characteristics at Wittenoom

\begin{tabular}{|c|c|c|}
\hline Characteristics & $\begin{array}{l}\text { Men } \\
(n=6505)\end{array}$ & $\begin{array}{l}\text { Women } \\
(n=411)\end{array}$ \\
\hline \multicolumn{3}{|l|}{ Year of first employment: } \\
\hline $1943-52$ & $22 \cdot 7$ & $19 \cdot 5$ \\
\hline $1953-57^{*}$ & $15 \cdot 6$ & 17.8 \\
\hline $1958-62$ & $33 \cdot 7$ & $29 \cdot 4$ \\
\hline $1963-67$ & $28 \cdot 0$ & $32 \cdot 8$ \\
\hline Unknown & 0.0 & 0.5 \\
\hline \multicolumn{3}{|l|}{ Age at first employment: } \\
\hline $10-24$ & $36 \cdot 6$ & $40 \cdot 1$ \\
\hline $25-34$ & $37 \cdot 1$ & $23 \cdot 4$ \\
\hline$\geqslant 35$ & $25 \cdot 1$ & $26 \cdot 2$ \\
\hline Unknown & $1 \cdot 2$ & $10 \cdot 2$ \\
\hline \multicolumn{3}{|l|}{ Nationality: } \\
\hline Australian & $22 \cdot 3$ & $33 \cdot 6$ \\
\hline Australian or British & $26 \cdot 7$ & $32 \cdot 8$ \\
\hline Other & $35 \cdot 1$ & $15 \cdot 6$ \\
\hline Unknown & 15.9 & $18 \cdot 0$ \\
\hline \multicolumn{3}{|l|}{ Worksite: } \\
\hline Mill only & $26 \cdot 3$ & $0 \cdot 5$ \\
\hline Mine only & $32 \cdot 5$ & $0 \cdot 5$ \\
\hline Mill and elsewhere $\dagger$ & $15 \cdot 5$ & $0 \cdot 5$ \\
\hline Mine and elsewhere† & $3 \cdot 3$ & 0.0 \\
\hline Neither mine nor mill & $12 \cdot 5$ & $90 \cdot 5$ \\
\hline Unknown & 9.9 & 6.8 \\
\hline \multicolumn{3}{|l|}{ Duration of employment: $\ddagger$} \\
\hline$<1$ month & $19 \cdot 3$ & $10 \cdot 7$ \\
\hline $1-3$ months & $25 \cdot 5$ & $27 \cdot 7$ \\
\hline 4-12 months & $32 \cdot 3$ & $33 \cdot 8$ \\
\hline $1-5$ years & $19 \cdot 4$ & $23 \cdot 8$ \\
\hline$>5$ years & $2 \cdot 7$ & $1 \cdot 0$ \\
\hline Unknown & 0.8 & 2.9 \\
\hline \multicolumn{3}{|c|}{ Estimated cumulative exposure to crocidolite: } \\
\hline$<10 \mathrm{f} / \mathrm{cc}$ years & $55 \cdot 8$ & $88 \cdot 1$ \\
\hline $10-100 \mathrm{f} / \mathrm{cc}$ years & $29 \cdot 1$ & $4 \cdot 1$ \\
\hline$>100 \mathrm{f} / \mathrm{cc}$ years & $4 \cdot 7$ & $0 \cdot 0$ \\
\hline Unknown & $10 \cdot 4$ & $7 \cdot 8$ \\
\hline
\end{tabular}

*A new mill began operation in September 1957.

†Mill and elsewhere includes mine, mine and elsewhere excludes mill. $\ddagger$ Minimum duration for those with some work periods of unknown duration $(0.3 \%)$.

one as a bagger.

Despite the known high fibre concentrations in the mill, most subjects accumulated less than an estimated $10 \mathrm{f} / \mathrm{ccy}$ of exposure and only $5.5 \%$ of men accumulated more than $100 \mathrm{f} / \mathrm{ccy}$. These observations are substantially explained by the comparatively short employment periods. The median estimated cumulative exposure to fibres was $6.0 \mathrm{f} /$ ccy in men and $0.5 \mathrm{f} /$ ccy in women.

\section{FOLLOW UP}

The vital status at 31 December 1980 was known for $73.2 \%$ of men and $58.0 \%$ of women (table 2 ). Totals of 135513 person-years of follow up were recorded in men and 8718 person-years in women if those lost to follow up were considered to be censured at 31 December 1980, and 95264 person-years in men and 4914 person-years in women if they were considered to be censored at the date last known to be alive.

To indicate the possible effects of loss to follow up on the results of the mortality analyses the percentages 
Table 2 Results of tracing of subjects to 31 December 1980

\begin{tabular}{|c|c|c|c|c|}
\hline \multirow{2}{*}{$\begin{array}{l}\text { Status at } \\
31 \text { December } 1980\end{array}$} & \multicolumn{2}{|l|}{ Men } & \multicolumn{2}{|c|}{ Women } \\
\hline & $\mathrm{No}$ & $\%$ & No & $\%$ \\
\hline $\begin{array}{l}\text { Dead } \\
\text { Alive }\end{array}$ & $\begin{array}{r}820 \\
3833\end{array}$ & $\begin{array}{l}12 \cdot 6 \\
58 \cdot 9\end{array}$ & $\begin{array}{r}23 \\
209\end{array}$ & $\begin{array}{r}5 \cdot 6 \\
50 \cdot 9\end{array}$ \\
\hline $\begin{array}{l}\text { Permanently emigrated } \\
\text { from Australia }\end{array}$ & 107 & $1 \cdot 6$ & 6 & $1 \cdot 5$ \\
\hline $\begin{array}{l}\text { Lost to follow up: } \\
\text { No follow up information } \\
\text { since end of employment } \\
\text { Traced after end of } \\
\text { employment but lost } \\
\text { before } 31 \text { December } 1980\end{array}$ & 1629 & $25 \cdot 0$ & 166 & $40 \cdot 3$ \\
\hline
\end{tabular}

of subjects with some follow up beyond termination of employment are shown within categories of demographic and work related characteristics in table 3. Follow up was generally greatest in those with complete identifying information and in those of Australian or British nationality who were employed recently and for long periods. Follow up was especially poor in those employed at Wittenoom for less than a month and this deficit is reflected in the low proportion followed up in the lowest category of estimated cumulative exposure to crocidolite.

\section{MORTALITY}

Table 4 shows the SMRs for all causes of death and categories of cause of death as defined by chapters of the ICD (9th revision) according to the two censoring methods. SMR1 (censored at 31 December 1980) for all causes was just under 1.0 in both sexes whereas SMR2 (censored at the date last known to be alive) suggested about a $50 \%$ increase in overall mortality.

In men, regardless of the method of estimation of the expected number of deaths, there was increased mortality from infectious and parasitic diseases, neoplasms, mental disorders, respiratory diseases, digestive diseases, and symptoms, signs, and ill defined conditions. For circulatory diseases, mortality was substantially less than expected under censoring method 1 (SMR1 = 0.67) and near that expected under method $2($ SMR2 $=1 \cdot 10)$. For injury and poisoning SMR1 was near unity whereas SMR2 was significantly increased above unity.

The few deaths in women limits the informativeness of cause specific mortality analysis. Mortality from neoplasms was increased only under method 2 (SMR2 $=1.99$ ). One of the 10 deaths from neoplasms was due to malignant mesothelioma of the pleura (MMP), two to other respiratory cancers (expected numbers of $1 \cdot 19$ and $0 \cdot 70$ under methods 1 and 2 respectively), two to cancer of the cervix, and one each to cancers of the breast, ovary, skin, tongue, and colon. There was no suggestion, on review of available records, that the cancers of the ovary and colon could have been peritoneal mesotheliomas. The two deaths from respiratory diseases (certified as due to chronic bronchitis and respiratory infection) were consistent with a twofold increase in mortality from these conditions. There was also a high mortality from digestive diseases based on two deaths, one from intestinal obstruction without hernia and one from cirrhosis of the liver. There was no suggestion, on review of available records, that the death due to intestinal obstruction could have been due to peritoneal mesothelioma. ICD chapters with only one or no female deaths were grouped together in the "all other causes" category. There were three such deaths, one from a motor vehicle accident, one from senile dementia, and one from nephritis.

To obtain more specific indications of the likely causes of increased mortality in men, the ICD chapters which contributed to excess mortality under both methods of calculation of expected numbers were subdivided into smaller categories of cause of death. To avoid artificially raised SMRs due to the poor specificity of cause of death coding for malignant pleural mesothelioma, ${ }^{14}$ subjects known from other

Table 3 Percentages of subjects with some follow up beyond termination of employment in categories of demographic and work related characteristics at Wittenoom

\begin{tabular}{|c|c|c|}
\hline Characteristics & $\begin{array}{l}\text { Men } \\
(n=6505)\end{array}$ & $\begin{array}{l}\text { Women } \\
(n=411)\end{array}$ \\
\hline \multicolumn{3}{|l|}{ Year of first employment: } \\
\hline $1943-52$ & $71 \cdot 6$ & 53.8 \\
\hline $1953-57$ & $76 \cdot 7$ & $56 \cdot 2$ \\
\hline $1958-62$ & $77 \cdot 2$ & $64 \cdot 5$ \\
\hline $1963-67$ & $74 \cdot 1$ & $61 \cdot 5$ \\
\hline Unknown & - & - \\
\hline \multicolumn{3}{|l|}{ Age at first employment: } \\
\hline $10-24$ & $78 \cdot 1$ & $55 \cdot 8$ \\
\hline $25-34$ & $74 \cdot 0$ & $74 \cdot 0$ \\
\hline$\geqslant 35$ & $75 \cdot 1$ & $72 \cdot 2$ \\
\hline Únknown & $8 \cdot 6$ & $9 \cdot 5$ \\
\hline \multicolumn{3}{|l|}{ Nationality: } \\
\hline Australian & $83 \cdot 1$ & $54 \cdot 3$ \\
\hline Australian or British & $76 \cdot 2$ & $59 \cdot 3$ \\
\hline Other & $71 \cdot 2$ & $75 \cdot 0$ \\
\hline Unknown & $69 \cdot 8$ & $56 \cdot 8$ \\
\hline \multicolumn{3}{|l|}{ Worksite: } \\
\hline Mill only & $74 \cdot 8$ & $50 \cdot 0$ \\
\hline Mine only & $75 \cdot 3$ & $50 \cdot 0$ \\
\hline Mixed including mill or mine & $82 \cdot 5$ & $50 \cdot 0$ \\
\hline Neither mine nor mill & $79 \cdot 9$ & $60 \cdot 5$ \\
\hline Unknown & $70 \cdot 1$ & $53 \cdot 3$ \\
\hline \multicolumn{3}{|l|}{ Duration of employment: } \\
\hline$<1$ month & $66 \cdot 6$ & $45 \cdot 5$ \\
\hline $1-3$ months & $73 \cdot 6$ & $53 \cdot 5$ \\
\hline $4-12$ months & $77 \cdot 1$ & $73 \cdot 5$ \\
\hline $1-5$ years & $80 \cdot 7$ & $73 \cdot 5$ \\
\hline$>5$ years & $92 \cdot 5$ & $75 \cdot 0$ \\
\hline Unknown & $49 \cdot 1$ & $66 \cdot 7$ \\
\hline \multicolumn{3}{|l|}{ Estimated cumulative exposure } \\
\hline to crocidolite: & & \\
\hline $\begin{array}{l}<10 \mathrm{f} / \mathrm{cc} \text { years } \\
10-100 \mathrm{f} / \mathrm{cc} \text { years }\end{array}$ & $\begin{array}{l}74 \cdot 6 \\
78 \cdot 2\end{array}$ & $\begin{array}{l}58 \cdot 5 \\
82 \cdot 4\end{array}$ \\
\hline $\begin{array}{l}10-100 \mathrm{t} / \mathrm{cc} \text { years } \\
>100 \mathrm{f} / \mathrm{cc} \text { years }\end{array}$ & 85.9 & $82 \cdot 4$ \\
\hline Unknown & $62 \cdot 9$ & $56 \cdot 2$ \\
\hline
\end{tabular}


Table 4 Mortality from all causes and in selected chapters of the International Classification of Diseases in men and women who worked in the production of crocidolite at Wittenoom, Western Australia

\begin{tabular}{|c|c|c|c|c|c|c|c|}
\hline \multirow[b]{2}{*}{ Cause of death } & \multirow[b]{2}{*}{$\begin{array}{l}\text { ICD } 9 \\
\text { chapter }\end{array}$} & \multicolumn{3}{|l|}{ Men } & \multicolumn{3}{|l|}{ Women } \\
\hline & & $\begin{array}{l}\text { Observed } \\
\text { deaths }\end{array}$ & $S M R 1^{*}$ & $S M R 2 \dagger$ & $\begin{array}{l}\text { Observed } \\
\text { deaths }\end{array}$ & $S M R l^{*}$ & $S M R 2+$ \\
\hline All causes & I-XVII & 820 & $\begin{array}{l}0.96 \\
(0.90-1.03)\end{array}$ & $\begin{array}{l}1.53 \\
(1.43-1.64)\end{array}$ & 23 & $\begin{array}{l}0 \cdot 85 \\
(0 \cdot 57-1 \cdot 29)\end{array}$ & $\begin{array}{l}1.47 \\
(0.98-2.21)\end{array}$ \\
\hline $\begin{array}{l}\text { Infectious and parasitic } \\
\text { diseases }\end{array}$ & I & 14 & $\begin{array}{l}1.77 \\
(1.05-2.99)\end{array}$ & $\begin{array}{l}2 \cdot 67 \\
(1 \cdot 58-4.51)\end{array}$ & $-\ddagger$ & - & - \\
\hline Neoplasms & II & 206 & $\begin{array}{l}1 \cdot 13 \\
(0 \cdot 99-1 \cdot 30)\end{array}$ & $\begin{array}{l}1 \cdot 83 \\
(1 \cdot 60-2 \cdot 10)\end{array}$ & 10 & $\begin{array}{l}1 \cdot 17 \\
(0 \cdot 63-2 \cdot 18)\end{array}$ & $\begin{array}{l}1.99 \\
(1.07-3 \cdot 70)\end{array}$ \\
\hline Mental disorders & $\mathbf{V}$ & 20 & $\begin{array}{l}2 \cdot 30 \\
(1 \cdot 48-3 \cdot 56)\end{array}$ & $\begin{array}{l}3 \cdot 66 \\
(2 \cdot 36-5 \cdot 68)\end{array}$ & $-\ddagger$ & - & - \\
\hline $\begin{array}{l}\text { Nervous system and } \\
\text { organ diseases }\end{array}$ & VI & 11 & $\begin{array}{l}1.02 \\
(0.57-1.85)\end{array}$ & $\begin{array}{l}1.63 \\
(0.90-2.95)\end{array}$ & $-\ddagger$ & - & - \\
\hline Circulatory diseases & VII & 248 & $\begin{array}{l}0.67 \\
(0.59-0.76)\end{array}$ & $\begin{array}{l}1 \cdot 10 \\
(0 \cdot 97-1 \cdot 25)\end{array}$ & 6 & $\begin{array}{l}0 \cdot 60 \\
(0 \cdot 27-1 \cdot 32)\end{array}$ & $\begin{array}{l}1.03 \\
(0.46-2.29)\end{array}$ \\
\hline Respiratory diseases & VIII & 83 & $\begin{array}{l}1.46 \\
(1 \cdot 18-1 \cdot 81)\end{array}$ & $\begin{array}{l}2 \cdot 50 \\
(2 \cdot 02-3 \cdot 10)\end{array}$ & 2 & $\begin{array}{l}1.72 \\
(0.43-6.89)\end{array}$ & $\begin{array}{l}2.99 \\
(0.75-12.08)\end{array}$ \\
\hline Digestive diseases & XI & 47 & $\begin{array}{l}1 \cdot 57 \\
(1 \cdot 18-2 \cdot 09)\end{array}$ & $\begin{array}{l}2.46 \\
(1 \cdot 85-3 \cdot 27)\end{array}$ & 2 & $\begin{array}{l}2 \cdot 17 \\
(0 \cdot 54-8 \cdot 69)\end{array}$ & $\begin{array}{l}3 \cdot 81 \\
(0 \cdot 95-15 \cdot 2)\end{array}$ \\
\hline Genitourinary diseases & $\mathbf{X}$ & 14 & $\begin{array}{l}0 \cdot 83 \\
(0 \cdot 49-1 \cdot 39)\end{array}$ & $\begin{array}{l}1 \cdot 33 \\
(0 \cdot 79-2 \cdot 24)\end{array}$ & $-\ddagger$ & - & - \\
\hline $\begin{array}{l}\text { Symptoms, signs and } \\
\text { ill defined conditions }\end{array}$ & XVI & 14 & $\begin{array}{l}1 \cdot 90 \\
(1 \cdot 13-3 \cdot 22)\end{array}$ & $\begin{array}{l}3 \cdot 03 \\
(1 \cdot 79-5 \cdot 11)\end{array}$ & $-\ddagger$ & - & - \\
\hline Injury and poisoning & XVII & 148 & $\begin{array}{l}1 \cdot 04 \\
(0 \cdot 88-1 \cdot 22)\end{array}$ & $\begin{array}{l}1.47 \\
(1.25-1 \cdot 73)\end{array}$ & $-\ddagger$ & - & - \\
\hline All other causes & $\underset{\mathbf{X I}-\mathbf{X V}}{\mathrm{III}, \mathrm{IV}}$ & 15 & $\begin{array}{l}0 \cdot 80 \\
(0 \cdot 48-1 \cdot 32)\end{array}$ & $\begin{array}{l}1.21 \\
(0.73-2.01)\end{array}$ & $3 \ddagger$ & $\begin{array}{l}0.95 \\
(0.30-2.93)\end{array}$ & $\begin{array}{l}1.64 \\
(0.53-5.07)\end{array}$ \\
\hline
\end{tabular}

*Subjects censored at 31 December 1980.

† Subjects censored at date last known to be alive.

¥All other causes for women includes chapters I, III-VI, and X-XVII.

sources of information to have died from this disease were excluded from the observed numbers of deaths in the causes of death to which they were coded on death certificates. Of the 32 such deaths, 19 were coded as pleural neoplasms (16 malignant, 3 benign), nine were coded as lung cancer ( 8 malignant, 1 undertermined nature), and two were coded as multiple malignancies without specification of site, one as lymphatic leukaemia and one as chronic interstitial pneumonia.

Table 5 shows the results of the mortality analyses for these smaller subdivisions of cause of death in men. Infectious and parasitic diseases - The SMR for tuberculosis was large under both censoring schemes $(2 \cdot 7$ and 4.1 respectively) and seemed to account for the excess of deaths from infectious and parasitic diseases. The other five deaths in this category were from unspecified viral diseases ( 2 deaths) and septicaemia, meningococcal meningitis, and actinomycosis (one each).

Neoplasms-Apart from pleural mesothelioma only neoplasms of the stomach $(\mathrm{SMR} 1=1 \cdot 2, \mathrm{SMR} 2=$ $1.9)$ and neoplasms of the trachea, bronchus, and lung $($ SMR1 $=1 \cdot 6$, SMR2 $=2 \cdot 6)$ showed raised SMRs under both censoring schemes. Among other neoplasms for which exposure to asbestos has been implicated as a possible cause, there was only one death from peritoneal mesothelioma ( 0 expected under both schemes) and there were two deaths from laryngeal cancer $(2.9$ and 1.8 expected under the two censoring schemes). There were half as many deaths from other neoplasms as expected under censoring scheme 1 but near to the number expected under scheme 2.

Mental disorders-All 20 deaths from mental disorders were due to alcoholism (19 coded to alcoholism and 1 to alcoholic psychosis) with $6 \cdot 3$ and $4 \cdot 1$ deaths expected under the two schemes.

Respiratory diseases - A large proportion of the excess deaths from respiratory disease was certified to pneumoconiosis ( 34 observed and 2.3 or 1.3 expected). There were 22 deaths due to bronchitis or emphysema ( 26.5 or 14.9 expected) and 26 to other respiratory disease ( 28.0 or 16.9 expected). These 26 consisted of 17 from pneumonia, five from chronic obstructive airways disease, and four from influenza.

Digestive diseases - There were large increases in mortality from both cirrhosis of the liver ( 25 observed, $9 \cdot 9$ or 6.3 expected) and peptic ulceration ( 12 observed, 7.6 or 4.8 expected). The 10 other deaths from digestive diseases included two from other liver disease, two from pancreatitis, and one each from intestinal volvulus, gastroenteritis, oesophageal disease, intestinal disease nos, disease of the stomach nos, and disease of the pancreas nos.

Symptoms, signs, and ill defined conditions - Of the 14 deaths in this category, 12 were coded as cause 
Table 5 Detailed analysis of mortality from infectious and parasitic diseases, neoplasms, mental disorders, respiratory diseases, digestive system diseases, and injury and poisoning in men

\begin{tabular}{|c|c|c|c|}
\hline Cause of death & Observed deaths & $S M R I$ & $S M R 2$ \\
\hline \multicolumn{4}{|l|}{ Infectious and parasitic diseases: } \\
\hline Tuberculosis & 9 & $2.72(1.42-5.24)$ & $4.09 \quad(2.13-7 \cdot 86)$ \\
\hline \multirow{2}{*}{\multicolumn{4}{|c|}{ Neoplasms:* }} \\
\hline Neoplasms of upper aerodigestive tract $\dagger$ & & & \\
\hline Neoplasms of oesophagus & $\begin{array}{l}5 \\
3\end{array}$ & $\begin{array}{l}0.85(0.36-2.05) \\
0.72(0.23-2.22)\end{array}$ & $\begin{array}{l}1.35(0.56-3.23) \\
1.18(0.38-3.66)\end{array}$ \\
\hline Neoplasms of stomach & 17 & $1.16(0.72-1.87)$ & $1.90(1.18-3.06)$ \\
\hline Neoplasms of intestines including rectum & 14 & $0.70(0.41-1.18)$ & $1.14(0.67-1.92)$ \\
\hline Neoplasms of pancreas & 7 & $0.76(0.36-1.59)$ & $1.21 \quad(0.58-2.55)$ \\
\hline Other digestive neoplasms $\ddagger$ & 2 & $0.45(0.11-1.81)$ & $0.71(0.18-2.85)$ \\
\hline Neoplasms of larynx & 2 & $0.68 \quad(0.17-2.74)$ & $1.09(0.27-4.35)$ \\
\hline Neoplasms of trachea, bronchus, and lung & 91 & $1.60(1.31-1.97)$ & $2.64(2.15-3.24)$ \\
\hline Malignant mesothelioma of the pleura§ & 32 & & \\
\hline Neoplasms of the prostate & 5 & $0.57 \quad(0.24-1.37)$ & $1.09(0.45-2.61)$ \\
\hline Lymphoma and myeloma & 6 & $0.63(0.28-1.40)$ & $0.97(0.44-2 \cdot 16)$ \\
\hline Other & 23 & $0.51 \quad(0.34-0.77)$ & $0.80(0.53-1.20)$ \\
\hline \multicolumn{4}{|l|}{ Mental disorders: } \\
\hline $\begin{array}{l}\text { Alcoholism } \\
\text { Other }\end{array}$ & 20 & $3 \cdot 16 \quad(2 \cdot 04-4 \cdot 89)$ & $4.87(3.14-7 \cdot 55)$ \\
\hline $\begin{array}{l}\text { Other } \\
\text { Respiratory diseases: }\end{array}$ & 0 & - & - \\
\hline \\
\hline $\begin{array}{l}\text { Pneumoconiosis } \\
\text { Bronchitis and emphysema }\end{array}$ & 34 & $15 \cdot 1(10 \cdot 8-21 \cdot 1)$ & $25 \cdot 5(18 \cdot 2-35 \cdot 7)$ \\
\hline $\begin{array}{l}\text { Bronchitis and empnysema } \\
\text { Other }\end{array}$ & 26 & $\begin{array}{l}0.83(0.55-1.26) \\
0.93(0.64-1.37)\end{array}$ & $\begin{array}{l}1.48 \\
1.54(0.91-2.27)\end{array}$ \\
\hline \multicolumn{4}{|l|}{ Digestive diseases: } \\
\hline Peptic ulceration & 12 & $1.58 \quad(0.90-2.79)$ & $2.48 \quad(1.41-4.37)$ \\
\hline Cirrhosis of the liver & 25 & $2.53(1.71-3.74)$ & $3.94(2.66-5.83)$ \\
\hline Other & 10 & $0.89(0.48-1.64)$ & $1.40(0.75-2.60)$ \\
\hline \multicolumn{4}{|l|}{ Injury and poisoning: } \\
\hline Transport accidents & 54 & $0.76(0.58-0.99)$ & $1.08 \quad(0.82-1.40)$ \\
\hline Other accidents & 53 & $1.62(1.23-2.12)$ & $2.36(1.81-3.09)$ \\
\hline SuicideT & 37 & $0.96(0.69-1.32)$ & $1.39(1.00-1.91)$ \\
\hline Homicide** & 4 & $1.38 \quad(0.52-3.68)$ & $1.96(0.74-5.22)$ \\
\hline
\end{tabular}

*Includes benign neoplasms and neoplasms of undetermined nature.

tLip, tongue, salivary glands, gum, floor of mouth, other mouth, oropharynx, nasopharynx, hypopharynx, other pharynx, nasal cavities. $=$ One death due to malignant mesothelioma of the peritoneum, one to digestive neoplasm nos.

$\S$ Of the 32 known cases of malignant pleural mesothelioma, 19 were coded as pleural neoplasms, nine as other respiratory neoplasms, three as other neoplasms, and one as pneumonia. They have been excluded from the latter three categories in the tabulation.

Includes late effects of all accidents.

IIncludes deaths due to injury not known whether self inflicted or not.

**Includes all purposefully inflicted injury except self inflicted injury.

unknown, one as dyspnoea, and one as asphyxia.

Injury and poisoning-Most of the excess mortality from injury and poisoning came from the 53 deaths due to non-transport accidents ( 32.7 or 22.5 expected) spread over many different causes as follows: accidental poisoning 6 , falls 11 , fires 4 , cataclysm 1 , drowning 6 , crushing 3 , choking 1 , machinery 4 (2 while employed at Wittenoom), electricity 3 , firearms 2 (1 while employed at Wittenoom), exposure 1, accidents NOS 8 ( 1 while employed at Wittenoom), complications in non-therapeutic procedures 2 , and late effects of a motor vehicle accident 1 . There were 54 deaths from transport accidents (71.1 or 50.0 expected) including 49 involving motor vehicles ( 1 while at Wittenoom), three involving railways (1 while employed at Wittenoom), and two involving aircraft.

There were 37 suicides ( 38.7 or 26.7 expected), two while still employed at Wittenoom, three violent deaths that were undetermined whether accidentally or purposefully caused, and four homicides (2.9 or 2.0 expected).

\section{DOSE-RESPONSE RELATIONS}

The figure shows the changes in age standardised death rates in four categories of time since first exposure to crocidolite for four major diseases of interest in three categories of cumulative exposure. The smaller estimates of person-years (censoring scheme 2) were used. There is evidence of an effect of exposure on mortality from lung cancer in both level of exposure and time from first exposure. In contrast the graph for stomach cancer shows no consistent evidence of dependence of mortality on crocidolite exposure. There were no deaths from this cause in the highest exposure group and only the lowest exposure group showed any increase in rate with time from first exposure.

To confirm that the raised death rate for stomach cancer was not due to misdiagnosis of peritoneal mesothelioma, a possibility suggested by Doll and Peto,' the bases for the death certificate diagnosis of the 17 deaths from stomach cancer were examined. Apart from four deaths that occurred before 1970, 

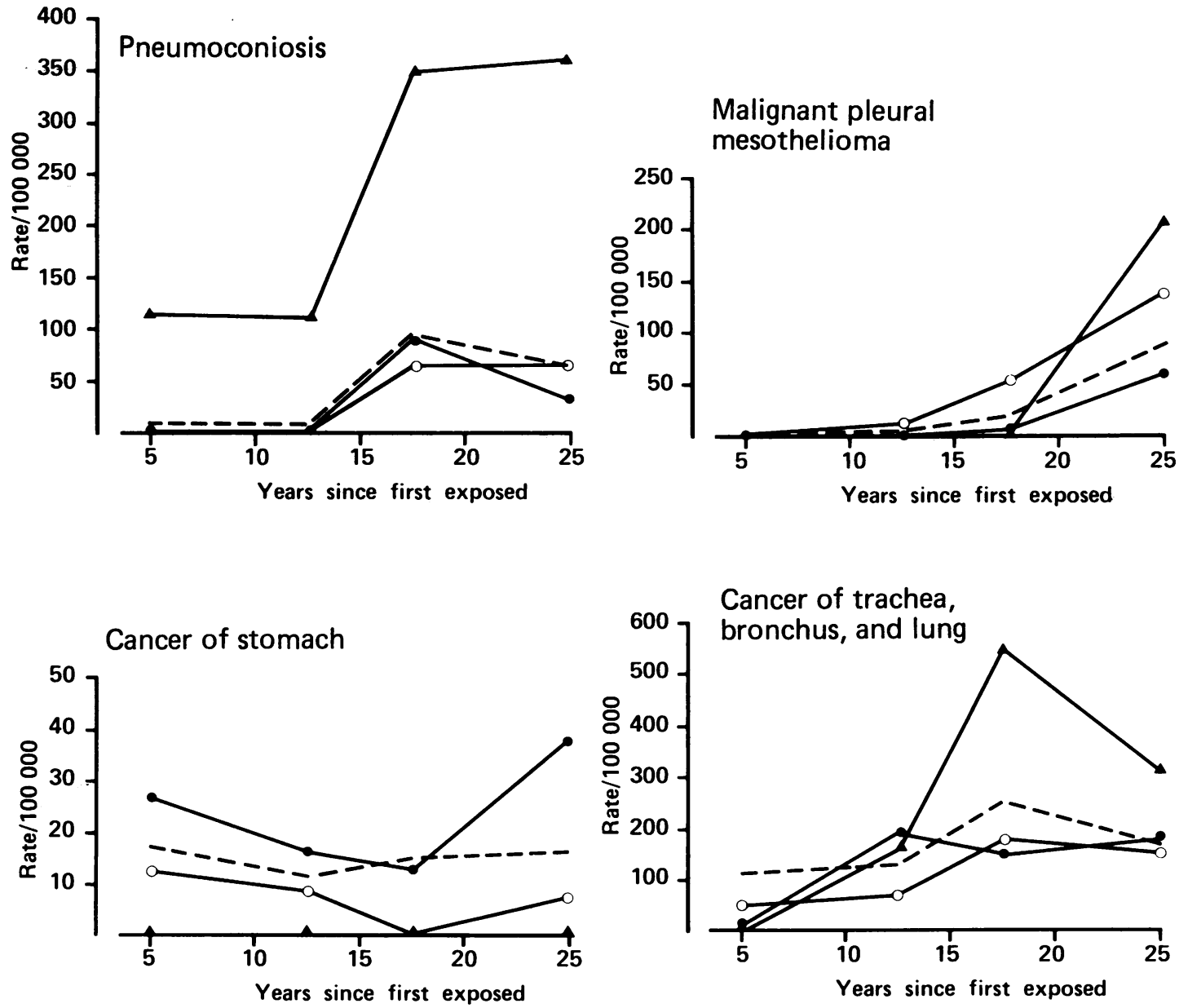

Age standardised death rates per 100000 person-years for specific causes by time since first exposed to crocidolite for different levels of total cumulative exposure to crocidolite.

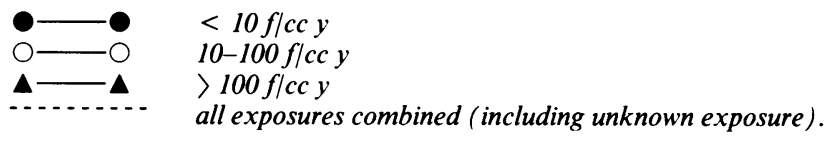

where the death certificate was the only data source, pathological information confirmed the diagnosis of stomach cancer in each case.

Mortality from mesothelioma was related to dose only after 20 or more years since exposure began. There were, therefore, indications of a longer induction period for mesothelioma than for lung cancer. The dose effect for pneumoconiosis, however, was evident much sooner after first exposure and there was a much greater difference between the highest exposure group and the lower ones than for the other diseases.

\section{Discussion}

This updated and detailed review of mortality in the cohort of crocidolite workers from Wittenoom Gorge has shown a similar pattern of disease to that previously observed. ${ }^{9}$ There were exposure related increases in mortality from pneumoconiosis, malignant pleural mesothelioma, and lung cancer. These increases were present in all exposure groups, including the lowest with $<10 \mathrm{f} / \mathrm{cc}$ y cumulative exposure to crocidolite. There were also increases in mortality attributed to tuberculosis, malignant neoplasms of the 
stomach, alcoholism, cirrhosis of the liver, peptic ulceration, and non-transport accidents for which other explanations are required.

The best estimate of the increase in overall or cause specific mortality in this cohort probably lies between that suggested by SMR 1 and that suggested by SMR 2 . It is most unlikely that all subjects who have not been traced are still alive as implied by SMR1. Many of the Wittenoom workforce were itinerant and many were migrants, newly arrived in Western Australia, who desired more remunerative and less unpleasant working and living conditions ${ }^{13}$ so that they did not stay in Wittenoom long. This is reflected in the data on duration of employment and the relation between it and the proportion successfully followed up. Their movements after leaving Wittenoom are only vaguely known. A proportion probably returned early to their country of origin, were missed in our search of departure records (available only after 1971) and have since died. In addition anecdotal information indicates that several people worked at Wittenoom under assumed names and changed their names on leaving. While the electoral roll of the Commonwealth of Australia is believed to cover some $98 \%$ of the population of Australia aged 18 and older (electoral registration is compulsory and the roll is carefully maintained) it is conceivable that the former workers at Wittenoom are over-represented in the $2 \%$ not on the roll, if only because of the high proportion of migrants, some of whom may never have become Australian citizens. We have no data that would allow us to estimate the relative contributions of these various factors to the incomplete follow up. It is difficult, therefore, to come to any firm conclusion as to where, between SMR1 and SMR2, the truth lies. We believe that it is probably nearer SMR2 than SMR 1.

Possibly more accurate SMRs could have been derived by assigning estimated follow up times to those lost to follow up on the basis of average follow up times for those with similar characteristics who had been traced ( $\mathrm{J}$ Kaldor, personal communication). This method, however, could lead to further confusion due to confounding of mortality with whichever characteristics were chosen, especially as the major difference between traced and untraced workers was in their duration of employment.

In contrast with the previous report on this cohort, ${ }^{9}$ attempts have been made here to relate mortality experience to fibre levels measured in the industry. The results indicate dose-response effects. Probably, however, cumulative dose was underestimated for most men because the measurements were performed towards the end of the working life of the industry when all dust suppression measures that had been instituted were in operation. As a result the estimates of potential of crocidolite fibres for causing disease may be exaggerated. Relative effects of particular dose levels, however, should be fairly accurate.

The rarity of peritoneal mesothelioma in this cohort in comparison with some others ${ }^{15}{ }^{16}$ has been noted before. ${ }^{9}$ Shipyard workers exposed to crocidolite, however, have also been noted seldom to develop peritoneal mesothelioma. ${ }^{17}$ Although Browne and Smithers showed a longer latent period for peritoneal than pleural mesothelioma ${ }^{18}$ others have shown no difference. $^{19}$ Other factors discriminating between mesothelioma sites were also discussed elsewhere ${ }^{18}$ but no firm conclusions were reached.

Other studies have noted similar excess numbers of cases of malignant mesothelioma and lung cancer in cohorts of crocidolite workers.' In this cohort there was an excess of lung cancer of 34 or 51 cases in men, depending on the method used to calculate expected numbers, compared with 32 mesotheliomas. The excess numbers are therefore similar for the two conditions although the high prevalence of smoking in the cohort ${ }^{2021}$ would account for some of the excess of lung cancer.

The increases in mortality from tuberculosis and stomach cancer in this cohort may be explained by the high proportion of migrants from continental Europe in the cohort who are known to have a high mortality in Australia from these diseases, ${ }^{22} 23$ indeed SMR2 for migrants for stomach cancer was 3.7 compared with 1.7 for Australian or British born workers. The high mortality from alcoholism and alcohol related conditions (cirrhosis of the liver and peptic ulcer) is consistent with a known high level of alcohol consumption in the Wittenoom workforce. ${ }^{13}$

Patterns of mortality similar to this cohort have recently been noted among a much smaller cohort of former vermiculite miners exposed to tremolite, ${ }^{24}$ another amphibole fibre. There was, however, a lower proportional mortality for mesothelioma and one of these four deaths was peritoneal in origin but a similar proportion of mesothelioma deaths has been seen among British asbestos workers employed before the introduction of their 1969 Control Regulations. ${ }^{25}$

The present analysis used conventional standardised mortality techniques and relies on the diagnostic accuracy of death certificates (except with respect to pleural mesothelioma). The expression of dose response relation in terms of cumulative dose is not as problematical $^{2627}$ for this cohort as it might be for others because of the relatively short durations of employment compared with duration of follow up. Further analysis of the data will concentrate on the exposure response relation for the separate diseases using within cohort comparisons with separation of dose level and duration and projections for future incidence of asbestos related disease. 
PS. A recent study of men retiring from a United States asbestos company and exposed primarily to chrysotile has, however, reported almost identical SMRs for both stomach cancer and tuberculosis. ${ }^{28}$

We gratefully acknowledge financial support from the National Health and Medical Research Council of Australia, CSR Ltd, and the Sir Charles Gairdner Hospital Research and Special Purposes Fund. Help with the estimation of exposure levels was provided by Mr G Major and Mr O Allan. The help of Mrs B Blunsdon, Mr D Atkinson, Mr A Lebrasse, Mrs J Eccles, MrS Woodward, Dr J Baker, Ms E Bingle, and Mrs A-M Haynes in collecting data and preparing this report is gratefully acknowledged.

\section{References}

1 Doll R, Peto J. Effects on health of exposure to asbestos. London: Health and Safety Commission, HMSO, 1985.

2 Jones JSP, Smith PG, Pooley FD, et al. The consequences of exposure to asbestos dust in a wartime gas-mask factory. In: Wagner JC, ed. Biological effects of mineral fibres. Lyon: International Agency for Research on Cancer, 1980:637-53. (IARC sci publ No 30.)

3 Wignall BK, Fox AJ. Mortality of female gas mask assemblers. $\mathrm{Br}$ $J$ Ind Med 1982;39:34-8.

4 Acheson ED, Gardner MJ, Pippard EC, Grime LP. Mortality of two groups of women who manufactured gas masks from chrysotile and crocidolite asbestos: a 40-year follow up. Br J Ind Med 1982;39:344-8.

5 McDonald AD, McDonald JC. Mesothelioma after crocidolite exposure during gas mask manufacture. Environ Res 1978;17:340-6.

6 Wagner JC, Sleggs CA, Marchand P. Diffuse pleural mesothelioma and asbestos exposure in the North Western Cape Province. Br J Ind Med 1960;17:260-71.

7 Talent JM, Harrison WO, Solomon A, Webster I. A survey of black mineworkers of the Cape crocidolite miners. In: Wagner JC, ed. Biological effects of mineral fibres. Lyon: International Agency for Research on Cancer, 1980:723-9. (IARC sci publ No 30.)

8 Botha JL, Irwig LM, Strebel PM. Excess mortality from stomach cancer, lung cancer and asbestos and/or mesothelioma in crocidolite mining districts in South Africa. Am J Epidemiol 1986;123:30-40.

9 Hobbs MST, Woodward SD, Murphy B, Musk AW, Elder JE. The incidence of pneumoconiosis, mesothelioma and other respiratory cancer in men engaged in mining and milling crocidolite in Western Australia. In: Wagner JC, ed. Biological efiects of mineral fibres. Lyon: International Agency for Research on Cancer, 1980:615-25. (IARC sci publ No 30.)

10 Major G. Asbestos dust exposure. In: Major G, ed. Proceedings of the first Australian pneumoconiosis conference, Sydney, 1968. Sydney: Joint Coal Board, 1968:467-74

11 Peto J. Man years computer program. Oxford: ICRF Cancer Unit, 1980.

12 Doll R. Comparison between registries, age-standardised rates. In: Waterhouse J, Muir C, Correa P, Powell J, eds. Cancer incidence in five continents. Vol III. Lyon: International Agency for Research on Cancer, 1976:453-547.

13 Layman L. Work and workers' responses at Wittenoom 1943-66. Community Health Stud 1983;7:1-18.

$14 \mathrm{Xu} \mathrm{Z}$, Armstrong BK, Blunsdon BJ, Rogers JM, Musk AW, Shilkin KG. Trends in mortality from malignant mesothelioma of the pleura, and production and use of asbestos in Australia. Med J Aust 1985;143:185-7.

15 Newhouse ML, Berry G. Patterns of mortality in asbestos factory workers in London. Ann NY Acad Sci 1979;330:53-60.

16 Selikoff IJ, Hammond EC, Seidman H. Mortality experience of insulation workers in the United States and Canada, 1943-1976. Ann NY Acad Sci 1979;330:91-116.

17 Blot WJ, Fraumeni JF. Cancer among shipyard workers. In: Peto R, Schneiderman M, eds. Quantification of occupational cancer. (Banbury report No 9.) New York: Cold Spring Harbor Laboratory, 1981:37-49.

18 Browne K, Smither WJ. Asbestos-related mesothelioma: factors discriminating between pleural and peritoneal sites. $\mathrm{Br} J$ Ind Med 1983;40:145-52.

19 Selikoff IJ, Hammond EC, Seidman H. Latency of asbestos disease among insulation workers in the United States and Canada. Cancer 1980;46:2736-40.

20 Cookson WO, de Klerk NH, Musk AW, Armstrong BK, Glancy JJ, Hobbs MST. The prevalence of radiographic asbestosis in crocidolite miners and millers at Wittenoom, Western Australia. Br J Ind Med 1986;43:450-7.

21 Baker JE. Lung cancer incidence amongst previous employees of an asbestos mine in relationship to crocidolite exposure and tobacco smoking. Perth: University of Western Australia, 1985. (PhD thesis.)

22 Chest and Tuberculosis Services Board. Annual report. Western Australia, 1984.

23 McMichael AJ, McCall MG, Hartshorne JM, Woodings TL. Patterns of gastro-intestinal cancer in European migrants to Australia: the role of dietary change. Int J Cancer 1980;25: 431-7.

24 McDonald JC, McDonald AD, Armstrong B, Sebastien P. Cohort study of mortality of vermiculite miners exposed to tremolite. $\mathrm{Br}$ $J$ Ind Med 1986;43:436-44.

25 Hodgson JT, Jones RD. Mortality of asbestos workers in England and Wales 1971-81. Br J Ind Med 1986;43:158-64.

26 Enterline PE. Pitfalls in epidemiological research. An examination of the asbestos literature. J Occup Med 1976;18:150-6.

27 Peto J. Some problems in dose-response estimation in cancer epidemiology. In: Vouk VB, Butler GC, Hoel DG, Peakall DB, eds. Methods for estimating risk of chemical injury: human and non-human biota and ecosystems. New York: Wiley and Sons, 1985.

28 Enterline PE, Hartley J, Henderson V. Asbestos and cancer: a cohort followed up to death. Br J Ind Med 1987;44:396-401 